\title{
Erratum
}

\section{Erratum to: Systolic Blood Pressure and Cognition in the Elderly: The Northern Manhattan Study}

Xiaoyan Sun, Chuanhui Dong, Bonnie E. Levin, Michelle Caunca, Adina Zeki Al Hazzouri, Janet T. DeRosa, Yaakov Stern, Ying Kuen Cheung, Mitchell S.V. Elkind, Tatjana Rundek, Clinton B. Wright and Ralph L. Sacco

Pre-press 25 October 2021

[Journal of Alzheimer's Disease, 82(2) (2021), 689-699, 10.3233/JAD-210252]

https://content.iospress.com/articles/journal-of-alzheimers-disease/jad210252

When this article was first published the fifth author's name was inadvertently misspelled as "Adina Zeki Al Hazzourie". This has been corrected to "Adina Zeki Al Hazzouri" in the revised online version of the article (DOI: 10.3233/JAD-210252).

Therefore, the correct updated list of authors and their affiliation is:

Xiaoyan Sun ${ }^{\mathrm{a}, \mathrm{b}}$, Chuanhui Dong ${ }^{\mathrm{a}, \mathrm{b}}$, Bonnie E. Levin ${ }^{\mathrm{a}, \mathrm{b}}$, Michelle Caunca ${ }^{\mathrm{a}, \mathrm{b}}$, Adina Zeki Al Hazzouri ${ }^{\mathrm{c}}$, Janet T. DeRosa ${ }^{d}$, Yaakov Stern ${ }^{d}$, Ying Kuen Cheung ${ }^{\mathrm{e}}$, Mitchell S.V. Elkind, ${ }^{\mathrm{c}, \mathrm{d}}$, Tatjana Rundek ${ }^{\mathrm{a}, \mathrm{b}}$, Clinton B. Wright ${ }^{\mathrm{f}}$ and Ralph L. Sacco ${ }^{\mathrm{a}, \mathrm{b}}$

${ }^{a}$ Department of Neurology, Miller School of Medicine, University of Miami, Miami, FL, USA

${ }^{\mathrm{b}}$ Evelyn F. McKnight Brain Institute, Miller School of Medicine, University of Miami, Miami, FL, USA

${ }^{\mathrm{c}}$ Department of Epidemiology, Mailman School of Public Health, Columbia University, New York, NY, USA

${ }^{\mathrm{d}}$ Department of Neurology, Vagelos College of Physicians and Surgeons, Columbia University, New York, NY, USA

e Department of Biostatistics, Mailman School of Public Health, Columbia University, New York, NY, USA

${ }_{\mathrm{f}}^{\mathrm{f}}$ National Institute of Neurological Disorders and Stroke, Bethesda, MD, USA 